\title{
Climate Inaction in Business Management: An Exploratory Review of the Literature
}

\author{
Alan F. Rodríguez-Jasso ${ }^{1}$, Arturo Briseño ${ }^{1}$ \& Ana L. Zorrilla ${ }^{1}$ \\ ${ }^{1}$ Facultad de Comercio y Administración Victoria, Universidad Autónoma de Tamaulipas, México \\ Correspondence: Alan F. Rodríguez, Facultad de Comercio y Administración Victoria, Universidad Autónoma de \\ Tamaulipas, México. E-mail: alan_rdz1@hotmail.com
}

Received: May 1, 2020

doi:10.5539/jsd.v13n4p87
Accepted: June 12, $2020 \quad$ Online Published: July 29, 2020

URL: https://doi.org/10.5539/jsd.v13n4p87

\begin{abstract}
Climate change is considered as one of the major threats for the international community due to its negative consequences in the financial, social, and environmental issues. Companies, who are considered as an essential element in the mitigation process, have exerted corporate inactivity to address climate change that has led to the increment of the greenhouse gas (GHG) emissions, contributing to climate change over the last decade. The objective of this review is to explore, summarize, and analyze the state of knowledge in the business and management literature about climate inaction that guides future researches to diminish this corporate inactivity, enhancing the practices aimed to reduce such emissions. The review was developed through the narrative method in order to acquire a broad perspective of the phenomenon through the examination of 24 articles from the Web of Science from 1998 to 2018. Our findings indicate that climate inaction is nascent and fragmented literature where the company is identified as one of the main actors, being this approach developed from different perspectives that guide to decrease such corporate inactivity, and motivating the corporate action. The inclusion of the concept of climate inaction might lead to an understanding of the mechanisms for climate mitigation, providing a guide for future research in the field of environmental performance.
\end{abstract}

Keywords: climate change, climate inaction in business, corporate environmental performance, emissions, greenhouse gas

\section{Introduction}

The globalization process makes possible interdependence among countries creating different benefits such as a greater integration in various aspects of the economy but also problems such as income polarization (Surugiu \& Surugiu, 2015). However, one of the main issues in the international field which concern the whole community is related to climate change (Falkner, 2016). Climate change is defined as a modification in the climate, where the composition of the atmosphere is altered due to the direct or indirect human activity, which can be observed during a period (United Nations, 1992). Conversely, the Intergovernmental Panel on Climate Change (IPCC, 2014) conceptualized climate change as a modification in the condition of the climate, where such changes stay for a long time, and it is caused by internal and external anthropogenic changes in the composition of the atmosphere. Both definitions coincide with the possibility that human influence is a catalyst for the existence of a new climatic regime (Kelman, 2015).

Such variations in the climate represent risks for human systems as well as for environmental ones, due to their complex interactions (IPCC, 2018). Derivate of the importance that represents climate change worldwide, this literature review focus on corporate climate inaction a key concept to understand how firms can create impacts in reducing emissions to the atmosphere.

Corporate climate inaction is conceptualized by Slawinski et al. (2017) as the absence in the reduction of greenhouse gas (GHG) emissions in absolute terms because of the lack of effective measurements. Besides, inaction can be considered in two situations: (1) the first is related to those companies who do not seek to achieve a reduction in their emissions through measurement, but inadvertently these emissions are reduced because of an improvement in their efficiency or a reduction in their production, and (2) when corporations do not reduce in absolute terms their emissions, but just in a marginal form. As a result, the importance of climate inaction is the recognition that marginal or involuntary reductions are not enough to consider them as an action to mitigate climate change. 
The corporate climate inaction effects can be observed not only in the environment but in the economy. For example, Stern (2006) mentions that the costs of such meteorological extremes events, such as storms, are rising with the increment of the temperature, where those costs will be increased according to the global warming for developed and undeveloped countries. For this reason, the reduction of the GHG emissions is considered as one of the main objectives, especially for corporations, to tackle climate change, where the motivations for such changes might be derived from the pressures of the stakeholders (Talbot \& Boiral, 2015).

The pressures from the stakeholders to climate change might be reinforced due to the more frequent events and its intensity, which might result in modifications, such as the increment in the sea level, affecting thousands of people (Amran et al., 2011). Hence, the lack of action addressed to the mitigation of GHG emissions carries a future not promissory, where the collapse of the food production, droughts, and sea-level increment are not acceptable (Mann \& Kump, 2015).

As a result, the objective of this paper is to develop a review of the literature on corporate climate inaction. This document presents the concept of corporate climate inaction and answers the question, what is the current situation related to this concept in the management literature? Our search was developed in the Web of Science (WOS) which provided us with 24 articles to analyze. We divide our findings into three sections, i.e. climate change, corporate climate inaction, and environmental performance.

\section{Climate Change}

The human being is continuously modifying the composition of the atmosphere and its proprieties since the preindustrial era, where the concentration of carbon dioxide $\left(\mathrm{CO}_{2}\right)$ has been increased mainly for the burn of fossil fuels, deforestation, and other uses of the land, which can trigger economic and environmental risks because the climate of the planet has been increased in at least $1^{\circ}$ Celsius (IPCC, 2018; Mann, 2014).

This environmental threat is latent for all kind of economies, especially for those developing one, such as Mexico and Latin American, due to it might be an obstacle in the poverty reduction actions, where those economies are more vulnerable because of their geographical exposition, low incomes, and its dependency in productive sectors sensible to the climate, such as agriculture, where a severe alteration in its local climate will lead them to present diverse social conflicts (Stern, 2006).

On the other hand, developed economies might be less vulnerable to those climate impacts because only a fraction of its economy is based on productive sectors sensitive to climate, and its economy is more flexible and adaptive, having liquid markets which allow them to address this climatic phenomenon in a better manner than developing economies (Thompson \& Otto, 2015; Tol et al., 2004).

For this reason, climate change is considered as a global issue that must be tackled collaboratively by developing and developed economies, establishing long-term objectives and agreements that accelerate climate action, and construct national and international perspectives (Stern, 2006). Therefore, the irreversible consequences, the contributions of the human activities, and the difficulties to adopt responsible environmental policies have made that stakeholders' pressures are being an important source of innovation in climate policy and collective action (Green, 2014; Mazutis \& Eckardt, 2017).

The urgency to address climate change for the international community is undeniable, and prompt actions are required (Mazutis \& Eckardt, 2017). For this reason, in 1988 the World Meteorological Organization (WMO) and the United Nations for Environment Programme (UNEP), established the Intergovernmental Panel on Climate Change (IPCC) to analyze the reasons of the climate problem and its possible consequences, as well as the actions required to be implemented by all society to tackle this climate crisis.

The actors engaged in the mitigations process are several; however, in figure 1 can be observed those international organizations that have a major influence on defining and implementing solutions related to climate change. The European Union (EU), IPCC, and companies are the institutions with major authority in the definition, design, and implementation of solutions towards this climate crisis, where the private sector is considered as the main contributor of GHG emissions, but at the same time, they have the necessary innovation to mitigate and decarbonize the world economy (Wright \& Nyberg, 2017). 


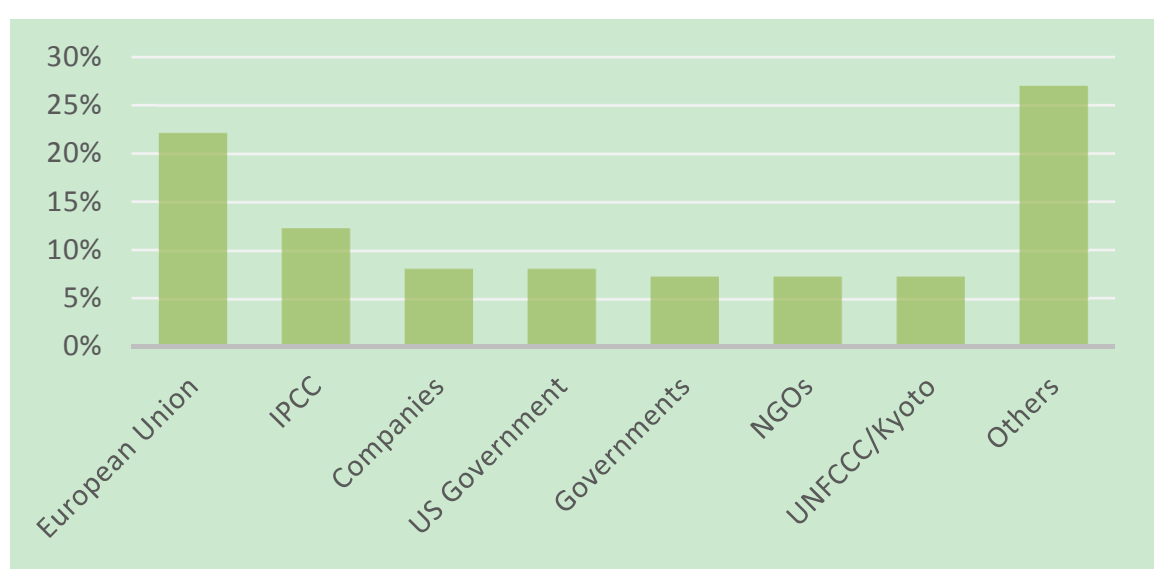

Figure 1. Most specific influential organizations on implementing solutions towards climate change

Source: Elaborated by the author based on GlobeScan (2006)

The influence that these actors have towards climate change mitigation is remarkable, that is the reason that IPCC determined to climate change as one of the most challenging threats of our era, considering it as a multi-faceted phenomenon due to its influence on environmental, economic and social aspects, where the consequences of climate inaction might be devastating and to avoid an increment in the global temperature is necessary (Grigoroudis et al., 2016; IPCC, 2018). The EU established an ambitious objective for 2030, which consists in reducing in at least $40 \%$ of the GHG emissions, being aligned with the Paris Agreement that includes limiting the temperature increment in $1.5^{\circ} \mathrm{C}$, a transition towards clean energies, legal obligations to adopt mitigation measurements, the establishment of a transparency framework, and the accountability of the results (European Comission, 2016).

The establishment of international agreements towards climate change has the support of different international actors; however, despite these initiatives, the $\mathrm{CO}_{2}$ emissions have increased and therefore, the global concentrations of these emissions have risen (Santillán \& De la Vega, 2018). This consequence has been developed because the economic tendency towards climate change has a neoclassical perspective, where the majority of the strategies and policies have been framed in this approach (De la Vega, 2015; Santillán \& De la Vega, 2018), getting unexpected outcomes of the implemented policies of the United Nations (UN) (Barrett \& Dannenberg, 2014).

The strategies and policies developed by different international organizations are based on the concentration of GHG emissions in the atmosphere. According to Stern (2013), the concentration of $\mathrm{CO}_{2}$ in the atmosphere is around 400 parts per million (ppm) in contrast to the $270 \mathrm{ppm}$ since the pre-industrial era. The concentration of these emissions has been increased from 2014-2018, going from 307 to 405.51 ppm during this period (Earth System Research Laboratory, 2018).

The current progress towards climate change is discouraging. There is a general pessimism related to the advances regarding climate change mitigation because the actions that have been taking are not enough (GlobeScan, 2019), as can be observed in figure 2. An urgent call for action is necessary, not just for the academic or government sector, but also for the private sector is necessary to increase the investment in order to get solutions concerning this climate crisis (Mazutis \& Eckardt, 2017). 


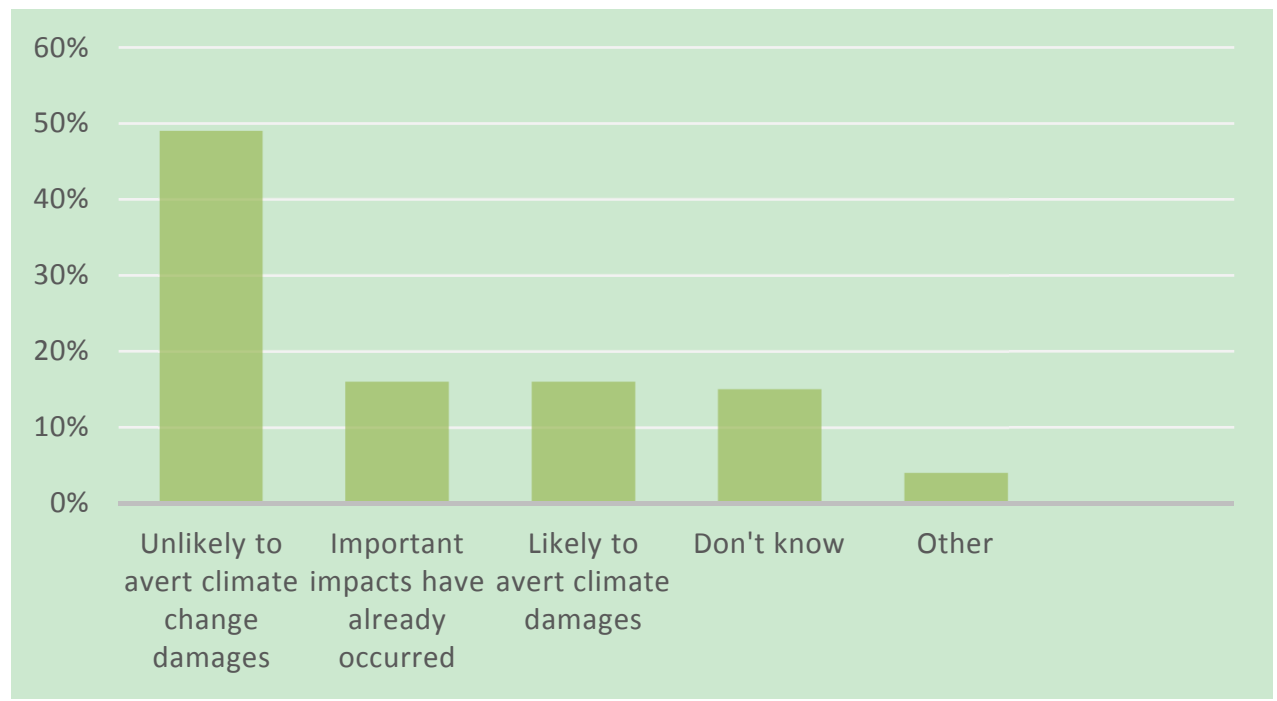

Figure 2. Progress on climate change

Source: Elaborated by the author based on GlobeScan (2019)

\section{Corporate Climate Inaction}

Climate change is an environmental phenomenon that requires global actions to mitigate the basic element for living, such as health, food production, clear air (Finke et al., 2016; Slawinski et al., 2017; Stern, 2006). One of the main emitters of GHG emissions is the private sector because the activities they performed have contributed to the historical increment of $\mathrm{CO}_{2}$, therefore, its role is preponderant in the mitigation process (Heede, 2014).

There is an international call to take action towards the mitigation process and decrease GHG emissions worldwide (Xiang et al., 2019). For this reason, it is necessary collaboration networks among companies, governments and society to get an integration related to the policies as well as strategic planning to tackle this phenomenon, making the collaboration an essential element of social transformation to achieve this global objective (Bamberg et al., 2015).

Despite the importance and relevance to maintain the global temperature below $1.5{ }^{\circ} \mathrm{C}$, the corporate inaction toward climate change is visible. Corporate climate inaction is defined as a lack of effective measurements towards an absolute reduction of GHG emissions, and not only in a marginal manner (Slawinski et al., 2017). The costs of inaction might be considerable, even higher to the prediction done by diverse models, highlighting the importance of urgent action for mitigation (Sterner, 2015).

The conceptualization suggested by Slawinski et al. (2017), emphasize that climate inaction is present when the firms do not achieve a permanent absolute reduction of the GHG emissions, but also when the proper measures are not considered to achieve those reductions. The economic impact of this corporate inaction is considerable, i.e. the social costs of China and the USA, which are considered as the main $\mathrm{CO}_{2}$ emitters worldwide, are around US\$16 trillion combined, where their social costs combined is around US\$400 per ton, in contrast with Canada and Russia with US\$10 per ton as social cost (Nature, 2018).

A permanent reduction of $\mathrm{CO}_{2}$ emissions might be achieved through a collaboration among corporations and governments. These organizations are capable to design, develop and implement solutions to tackle climate change, where collaboration might lead to positive outcomes, increasing the probabilities to achieve the mitigation objective (GlobeScan, 2019), as is showed in figure 3, where the private sector has a fundamental role to tackle climate change. 


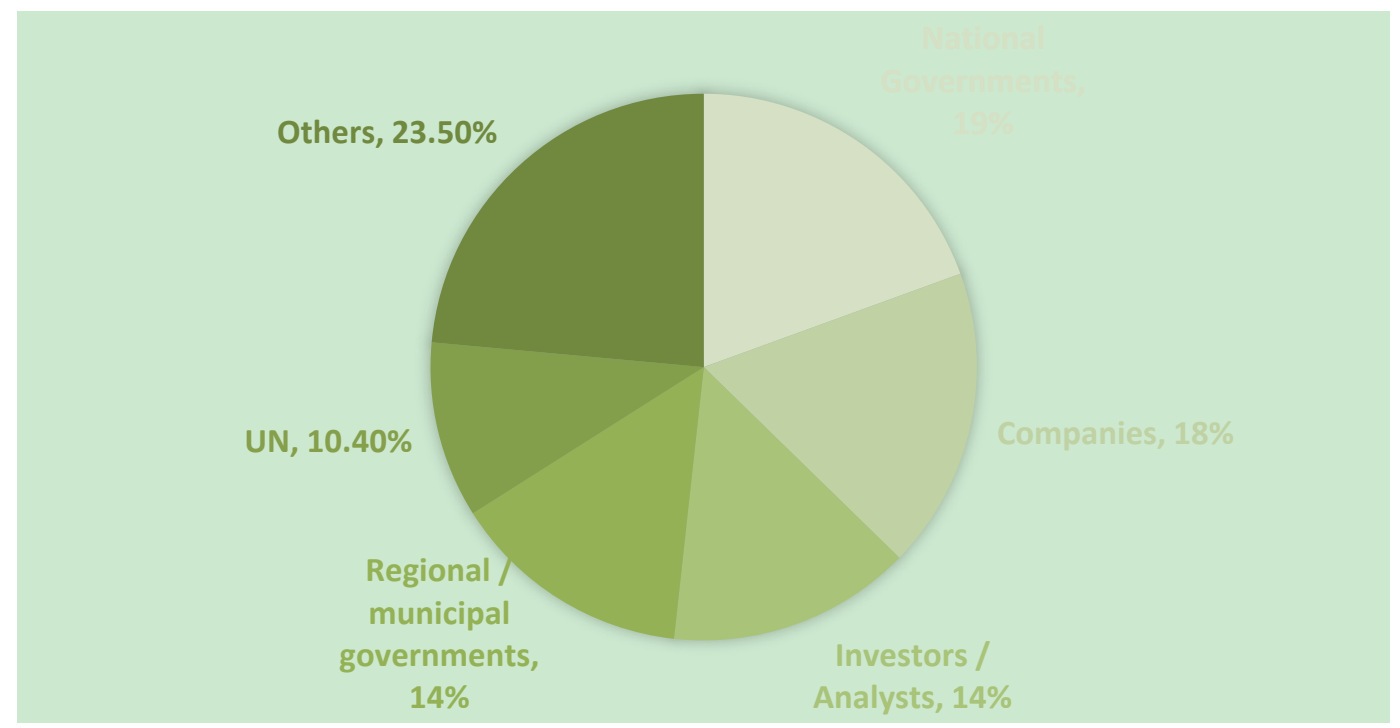

Figure 3. Organizations with more capabilities to implement solutions towards climate change

Source: Elaborated by the author based on GlobeScan (2019)

The relevance of the private sector in the international field is remarkable because it is considered a necessary element of the global economy. Derived from its importance, companies have engaged in sustainable issues during the last decade, calling the attention of academics and practitioners, who have implemented the results from these researches to obtain a competitive advantage and maintain their legitimacy with their stakeholders (Slawinski et al., 2017).

The threat that represents climate change requires that different actors, such as corporations, governments, and society, develop long-term solutions because of the lack of measures established by the government and the absence of a society strength, generate the responsibility for corporations to create solutions to the sustainability threats that they have contributed to create and develop (Azlan Amran et al., 2016). In consequence, an increasing number of firms have taken an active role in climate issues, implementing strategies based on energy and carbon consumption and therefore, contribute to GHG mitigation (Sullivan \& Gouldson, 2017).

Governments are considered as one of the main organizations with a major influence on climate solutions; nevertheless, the private sector is another actor with capabilities to take an active role in the coming years caused by their economic capacity, research, and development, as well as academic and research institutions, as knowledge generators, can contribute to the achievement of this climate objective considering their capabilities to design and implement strategies with other actors, addressing this climate crisis in a better manner, as figure 4 shows (Knuth et al., 2007). 


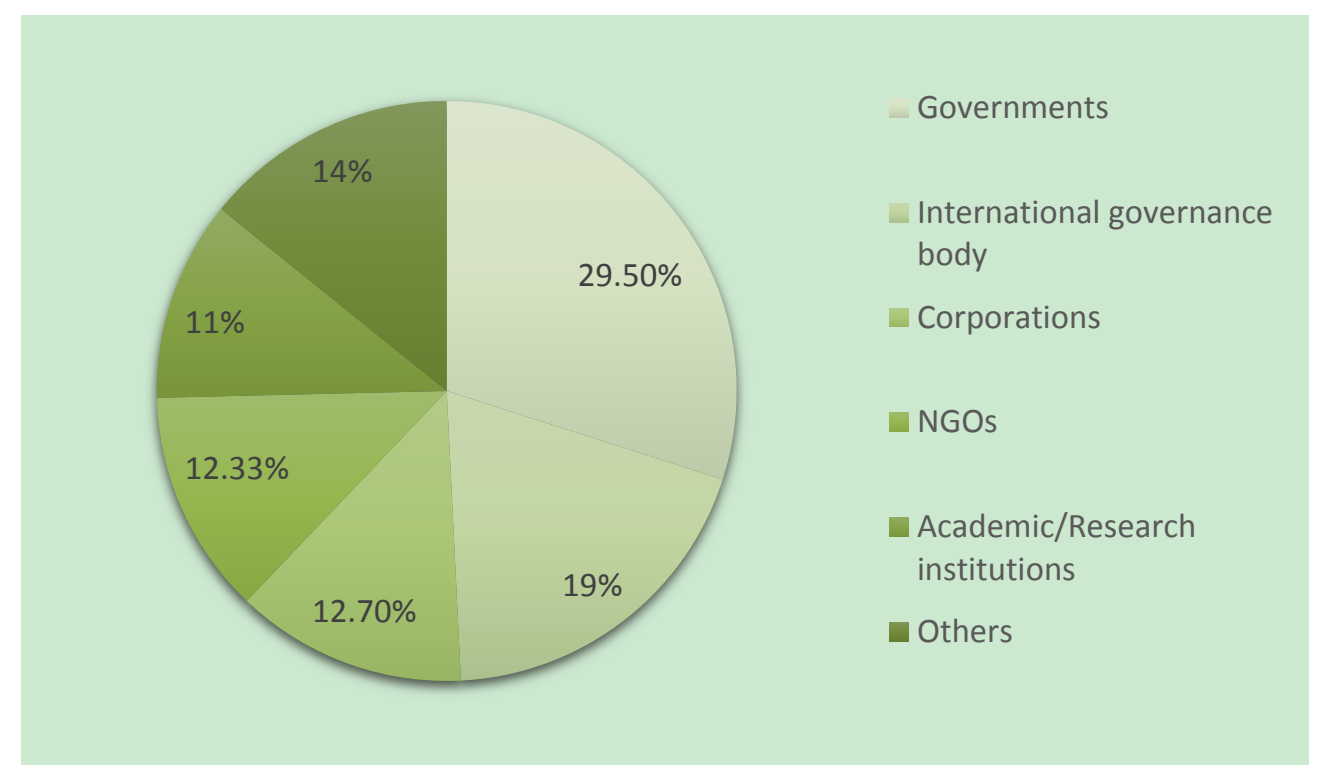

Figure 4. Most influential type of organizations on implement solutions towards climate change

Source: Elaborated by the author based on GlobeScan (2006)

A collaboration among actors is necessary to motivate an effective implementation of environmental management, which has encouraged to examine the barriers towards this implementation; however, the phenomenon of inaction remains intact (Slawinski et al., 2017). Hence, Hoffman \& Bazerman (2007) suggest that the cognitive barriers towards sustainability action are related to the individual's conceptualization in the relation competitively sustainability, and associate it as win-lose, where the competitively is chosen over sustainability.

For this reason, table 1 explains two important conditions related to organizational inaction towards climate change. The first situation is centered that companies do not involve in the establishment of a specific measure for a longterm and this manner reduce their emissions, but their reductions are derived from improvements in their performance or decrement of the production, and it is not related to effective mitigation measures, which is considered as climate inaction (Slawinski et al., 2017).

The second condition is concerning the lack of absolute GHG emission reduction, in order words, the emission reduction has not a considerable impact, therefore a company might be considered as inactive when its abatement is marginal through different measures focusing only in carbon efficiency (i.e. GHG emission measures by unit produced) instead of absolute, and permanent contractions because those limited decrements are countered by general increments in production (Slawinski et al., 2017). Consequently, continuous carbon efficiency is necessary; however, it is an insufficient and effective action towards climate change (Ehrenfeld \& Hoffman, 2013). 
Table 1. Corporate climate inaction

\begin{tabular}{|c|c|}
\hline GHG emissions & Corporate measurements \\
\hline Absolute reduction & $\begin{array}{l}\text { Inaction is not present because there are effective } \\
\text { actions to mitigate climate change. }\end{array}$ \\
\hline Relative reduction & $\begin{array}{l}\text { Inaction is present when there is an action; however, } \\
\text { it is not sufficient to have a considerable impact } \\
\text { because an increment in the production could } \\
\text { neutralize such improvement. } \\
\text { Inaction is not present when there is a reduction due } \\
\text { to efficient improvement; nevertheless, it is not } \\
\text { enough to create a substantial effect on climate } \\
\text { change. }\end{array}$ \\
\hline \multirow[t]{2}{*}{ No reductions } & $\begin{array}{l}\text { Inaction is present when there is not any symbolic } \\
\text { action about climate change. }\end{array}$ \\
\hline & $\begin{array}{l}\text { Inaction is considered as not present when climate } \\
\text { change is not included in the corporate agenda. }\end{array}$ \\
\hline
\end{tabular}

Source: Elaborated by the author based on Slawinski et al. (2017)

For a better understanding of corporate climate inaction, it is important to examine the current challenges that it represents for the economy and environment as well as the limited time to avoid the negative consequences of this climate crisis, where the call for action is urgent to reduce GHG emissions effectively (Chen et al., 2017; European Comission, 2016; IPCC, 2014).

The urgent call for action is concerning the time that GHG emissions remain in the atmosphere, where the dangerous threshold might have trespassed, and the physical impacts could be worse (IPCC, 2014). For example in May 2013, it was registered $400 \mathrm{ppm}$ of $\mathrm{CO}_{2}$ in the atmosphere, which is the first time in history that the level of carbon dioxide concentration raises in this manner, establishing a new limit for climate change (Carrington, 2013).

The necessity to take action is undeniable, due to the companies must establish specific target emissions to become carbon neutral, and in this manner address the negative impacts of climate change within the next decade, which might be the most important period to tackle effectively the climate crisis that has been increasing since the preindustrial era, and obtaining competitiveness within the industry (GlobeScan, 2019), as we can see in figure 5. 


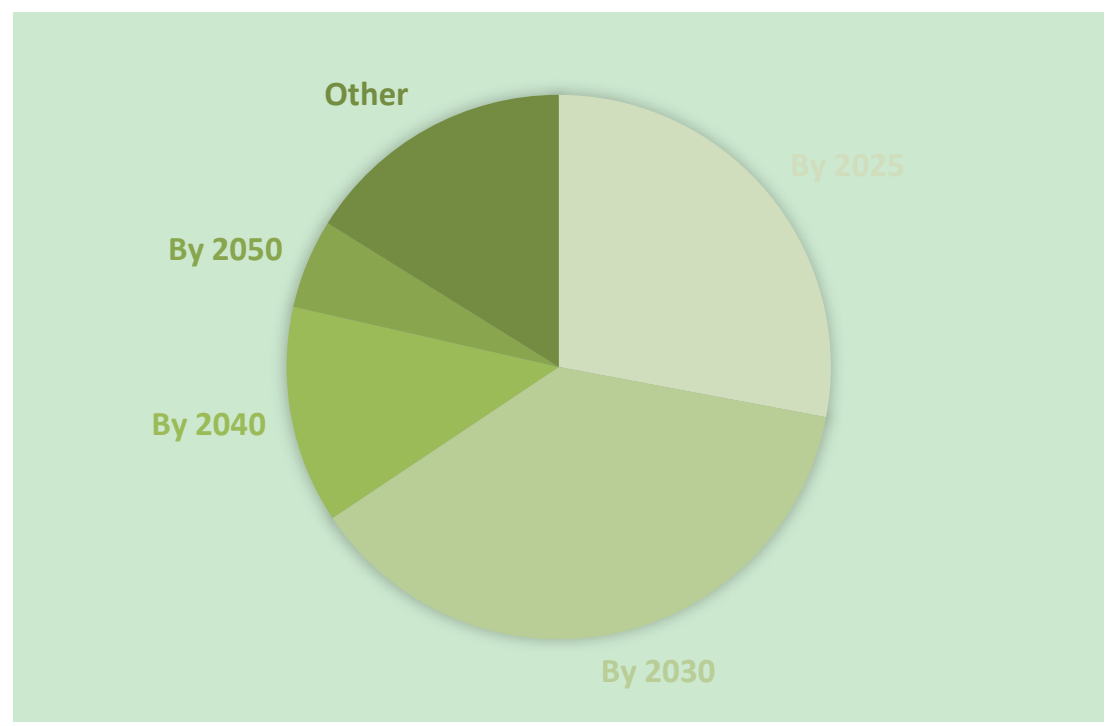

Figure 5. Corporate carbon-neutral expectations

Source: Elaborated by authors based on GlobeScan (2019)

The consequences that might have this crisis could affect the productive sectors for the economy, such as industry and infrastructure, agriculture, among others, resulting from its dependency on variations in the climate, where the effects of these climate modifications might be felt in different latitudes; however, such repercussions are preventable with an effective policy implementation (Ackerman \& Stanton, 2006; Hope, 2006).

Hence, inadequate addressing this climate crisis by companies might exert a negative influence on the firm's key stakeholders, affecting the corporate profits, revenues, a lack of access to capital and investments, which could derive in a barrier on the corporate growth, increasing the risk to lose legitimacy and therefore, in the corporate survival (GlobeScan, 2019), as we can see in figure 6.

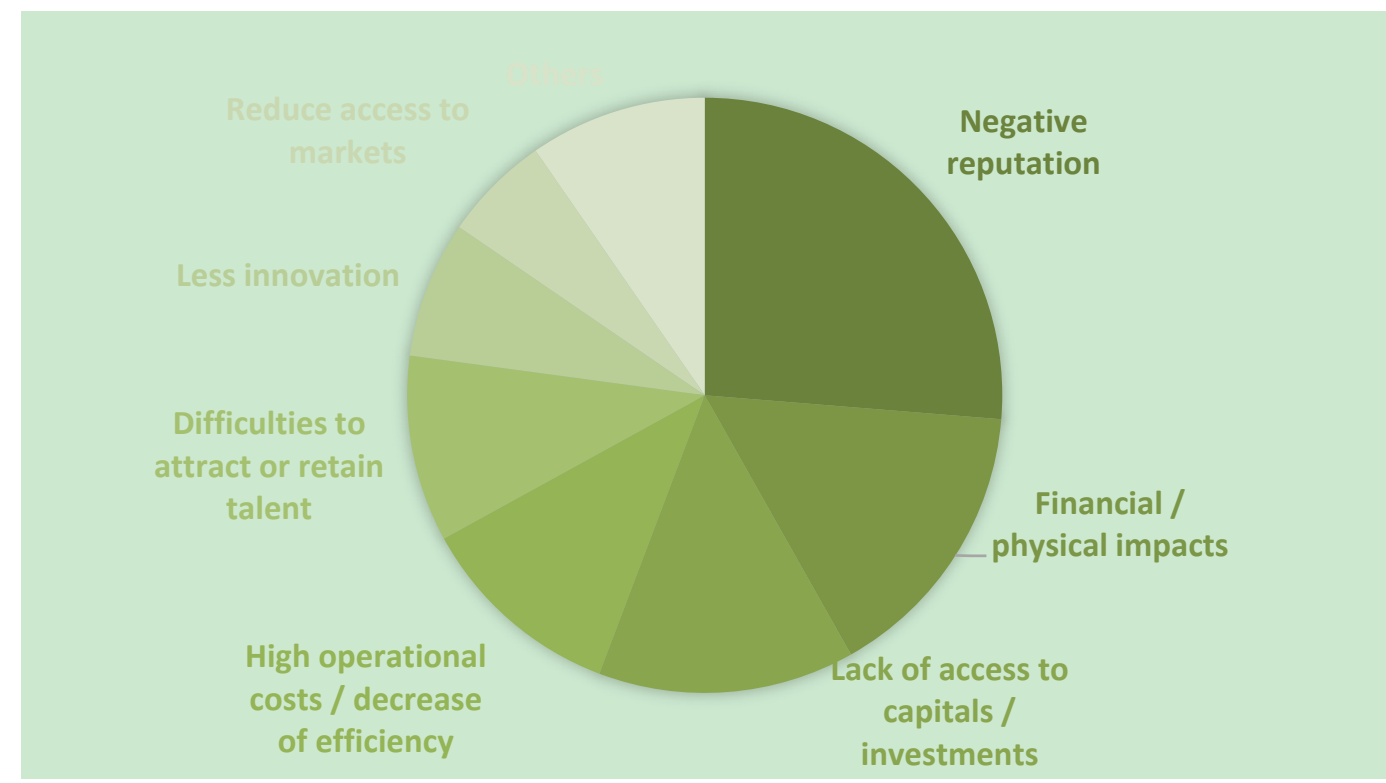

Figure 6. Consequences of not addressing climate change

Source: Elaborated by authors based on GlobeScan (2019)

Even though the urgency and interest to take action is remarkable, certain researches indicate that the optimal policy for climate change mitigation is the inaction (Ackerman \& Finlayson, 2006). In this model, three aspects 
were modified, including discount rate, benefits of moderate global warming, and the treatment of the most advanced climate science, resulting in a short on a recommendation to mitigate GHG emissions.

Another research was developed by Butler et al. (2014) considering the benefits and costs of stabilization climatic policies using the model IAM (Integrated Assessment Models), where the costs and damages related to this climatic threat are underrated caused to the negligence to the uncertainty towards $\mathrm{CO}_{2}$ stabilization minimize such risks.

Climate change has been denominated a predictable surprise because the different actors are unaware of the negative effects that it might cause, where the leaders and decision takers had all the necessary information to take action and anticipate its possible consequences, making the concept of climate inaction, a relevant concept to mitigate (Burbidge, 2015).

\section{Corporate Environmental Performance}

One of the fields that have shown an increasing dynamism during the ' 90 s, related to management and corporate strategy, is the recognition and response to environmental issues by the private sector, which has been called "Greening", about the process where the human activity is compatible with the natural environment (Kenis \& Lievens, 2015).

Within this environmental compatibility, companies have designed, developed, and implemented policies and programs to satisfy the opportunities and environmental restrictions in response to the social awareness towards the natural environment, based on the role that public and private organizations represent for the GHG mitigation and their impact on the natural ecosystems and human wellbeing (Amran et al., 2011; Silveria \& Puppim, 2015).

Consequently, the importance of the natural environment has increased for different actors, such as consumers, shareholders, investors, creditors, regulators, employees, and society (Guenther et al., 2015), where the attention is based on the corporate environmental performance (CEP) related to measurements, which are becoming essential for the decision making within the organization (Costoiu et al., 2016).

The measurement and evaluation of corporate performance is a difficult task to achieve, due to the lack of consensus towards the most appropriate indicators for corporate efficiency (Cameron, 1986). Therefore, one common way to evaluate it is through the corporate financial performance (CFP) (Chakravarthy, 1986); however, considering the current relevance of the natural environment, it is important to take into consideration the inclusion of this element in such assessments, responding to the social and regulatory expectations (Xie et al., 2018).

Through environmental measurements, corporate performance might be obtained, which is defined by Post et al. (2015) as the different environmentally responsible practices and their results on the company's activities, and their impact on the natural environment. These practices can vary substantially, moving from proactive approaches that require building-specific capacities and resources, to reactive solutions that meet the minimum regulatory standards (Hart, 1995).

In this way, corporate governance plays a key role in the environmental performance of organizations. Firstly, these initiatives require substantial investments in environmental management, which have strategic implications within the institution for achieving the sustainability objective (Alrazi et al., 2015). These implications can be risky, but at the same time, it might have a positive impact on the capital and viability of the firm (Walls et al., 2012). Secondly, multi-level coordination that extends to the various levels of the firm is required to achieve the main objective (Howes et al., 2015).

As a result, the need of information regarding environmental performance has led that different groups, which include regulatory agencies, corporations, the business press, and entrepreneurs, to pressure the organizations to develop a series of measurements to capture various elements of this performance, improving the financial attractiveness for investors as well as improving the stakeholder's perceptions (Li et al., 2017). These evaluations have been used by companies to measure and report information related not only to the environmental issues but to the social, and governance aspects since an increasing number of investors use this information as a support in their decision-making (Zadeh \& Serafeim, 2017).

There is a variety of criteria that can be used to evaluate the CEP, where these assessments are a mixture of environmental programs, management structures, corporate responsibilities, relations with internal and external groups, to create long-term business financial value (Barman, 2018). Consequently, the CEP indicators are usually divided into three main categories: 1) environmental impact, where the attention is towards GHG emissions, and the electrical energy used; 2) regulatory compliance, which is related to the company's non-compliance status, the infringement fees as well as the number of audits; and finally 3) the organizational process, which is focused on environmental accounting, audits, reports, and the environmental management system (Ilinitch et al., 1998), where 
companies use different elements of these categories to base their possible future investments (Delmas \& Blass, 2010).

The main trade-offs involved in the measurement and evaluation of CEP, according to Delmas \& Blass (2010) include positive and negative evaluations; environmental and corporate performance criteria; past, present and future performance; and finally, related to what can be measure and what should be, as we can see in table 2 .

Table 2. Main trade-offs of CEP

\begin{tabular}{ll}
\hline \multicolumn{1}{c}{ Trade-offs } & \multicolumn{1}{c}{ Description } \\
\hline Positive and negative evaluations & Sustainable investors can use positive and negative \\
& methodologies to exclude those companies with poor \\
& performance and support those with high \\
& accomplishment.
\end{tabular}

$\begin{aligned} & \text { Environmental and corporate performance } \\ & \text { criteria }\end{aligned}$
$\begin{aligned} & \text { a direct impact on corporate operation performance } \\ & \text { over those with less effect on the firm's operations } \\ & \text { but could have a bigger environmental influence. }\end{aligned}$

Past, present, and future performance

What can be measured and what should be
It is focused on management and reporting practices as a proxy for future performance at expenses of the present achievement.

Based on the fact that data available is scarce, there is a trade-off between the ability to use databases that might not be the most relevant, and the use of detailed and important data that is available for a small number of companies.

Source: Elaborated by the author based on Delmas \& Blass (2010)

Organizations that show low performance and environmental compliance tend to provide better sustainability reports and adopt more prevention activities against environmental pollution, such as GHG emissions, so that, information disclosure increases the corporate credibility (Haque \& Azizul, 2015; Ilinitch et al., 1998), turning corporate transparency into a competitive element, which might generate trust among the company's stakeholders to obtain a differentiation, which can be translated into benefits for the firm (Amran et al., 2011).

\section{Method of Study}

This study is to conduct a narrative literature review to know the current situation of climate inaction within business and management. In order to achieve this goal, we followed Tranfield et al. (2003) by establishing the research question as a guide in the review process. Throughout this section, the research concepts are clarified, then we discuss the motivation to select a narrative literature review as our research approach, and finally, we present the research design proposed for our analysis.

The purpose of a literature review is to report objectively the current knowledge about a topic and settle such information in perspective, recapitulating the state of the art, providing the reader with comprehensive information for a clearer understanding and a general picture of the major accomplishments, as well as identify the gaps into literature (Green et al., 2006; Pautasso, 2019).

The approaches and reasons for summarizing literature vary according to the research question, which is a key element that guides the project to be developed (European Food Safety Authority, 2010). For example, Grant \& Booth (2009) identified 14 types of published reviews that are not mutually exclusive, where the research 
question indicates the type of approach to be followed. According to Grant \& Booth (2009), when the research question requires the answer for a specific inquiry rather than a broad understanding, a systematic review could be used because with this approach is possible to envision that the specific question would result in a parameter that is within the sample distribution. On the other hand, when the objective is to know the current state of knowledge about a particular subject, a narrative review might be the most appropriate approach.

For this review, we conclude that the narrative literature review accomplishes with the main objective of this study since we aim to analyze, summarize, and deliver a comprehensive understanding of the current state of knowledge related to climate inaction in business, gathering the pieces together to present a broad perspective about this climate issue (Pautasso, 2019; Slavin, 1998). This perspective allows us to combine distinct qualitative and quantitative studies that tackle the research questions using different methodologies, provoking thoughts and stimulating the dialogue among the readers (Baumeister, 2013; Green et al., 2006).

\subsection{A Narrative Literature Review Protocol}

The literature review protocol is a plan that improves the objectivity of the process, providing a transparent description of the steps taken within the procedure, comprising information to address the research question, the sample of the study, the data gathering, as well as the inclusion and exclusion criteria (Tranfield et al., 2003). In table 3 we can see the protocol used in the development of this study.

Table 3. Narrative literature review protocol

\begin{tabular}{|c|c|}
\hline \multicolumn{2}{|r|}{ Literature review protocol } \\
\hline Step & Description \\
\hline 1 & Definition of the purpose of the review \\
\hline 2 & $\begin{array}{l}\text { Identification of the research } \\
\text { - Definition of sources of information } \\
\text { - Keywords definition and search terms } \\
\text { - Defining the period of search }\end{array}$ \\
\hline 3 & $\begin{array}{l}\text { Search terms and delimitating } \\
\text { - Utilization of the Web of Science database } \\
\text { - Search by topic } \\
\text { - Using the defined keywords and search terms selected } \\
\text { - Selection of all the years }\end{array}$ \\
\hline 4 & $\begin{array}{l}\text { Selection criteria employed } \\
\text { - Inclusion criteria and exclusion criteria }\end{array}$ \\
\hline 5 & $\begin{array}{l}\text { Study assessment } \\
\text { - } \quad \text { Title and abstract review } \\
\text { - } \quad \text { Full-text analysis }\end{array}$ \\
\hline
\end{tabular}

Source: Elaborated by authors

To recapitulate the stand of the knowledge related to climate inaction in business, and obtain a broad perspective of this issue, we defined the purpose of the review through the alignment of the key elements of the research to get a picture of the state in the management field (Green et al., 2006; Pautasso, 2019). First, we determined to use the Web of Science as an engine to explore and analyze the studies. Then, we decided to select those articles that matched the keywords and main concepts of the studies. We defined to select the terms: "CORPORATE CLIMATE INACTION", "CLIMATE INACTION", and "ORGANIZATIONAL CLIMATE INACTION" excluding those related to national, regional, and municipal governments for the case of the last two, which might not fit in the objective of the research due to the perspective applied. Based on the relative novelty of the issue in the field, we resolved to consider manuscripts within the range of time 1998 - 2018, and we determined not to restrict our research to any range of quality of the journal.

Following the protocol, and once defined the selection criteria of the papers. The inclusion criteria was based on 
the selection of those articles that belong to the Management, Business, Finance, and Economics categories that matched the keywords previously established. The second criterion was to include peer-review journal articles. Concerning the time, we delimitate the period of research. Hence, our final sample consisted of 24 studies to analyze in a more depth manner.

Green et al. (2006) suggest that a narrative review involve a rigorous and detailed examination of the published literature, which is used to provoke thought and controversy among the readers, and at the same time, provide a summary related to a research area to get an understanding of a particular phenomenon (Duke \& Bennett, 2010). In order to achieve this objective, we realized the study assessment into two steps. The first one consisted of a review focused on the title and abstract of each manuscript to identify the topic addressed, the research question, and the purpose of the study. The second stage consisted of the identification of the variables used, the data sources, and the main results, with the objective to provide an understanding of current state into management and business literature related to climate inaction.

\section{Discussion}

Throughout this literature review, a greater international interest focused on climate change is identified. Several studies highlight the potential risks of not taking action to mitigate climate change, and therefore, the consequences of this organizational inaction might be significant in the financial and social aspects, where the private sector has an essential role in the designing, development, and implementation of strategies to address climate change impacts, considering that this sector has contributed in a significant manner to the increment of the GHG emissions over the last decades (Ackerman \& Stanton, 2006; Stern, 2013).

This review distinguishes three main topics in the literature towards 1) climate change, 2) climate inaction, and 3) environmental performance. First, climate change demands an international collaboration focused on climate mitigation where the decrement of the GHG emissions is fundamental, due to the threat it represents for nature and human wellbeing (Funfgeld, 2015), but at the same time, it brings opportunities for developed and developing economies, where its private sector might transform this threat into a competitive advantage, and improve its reputation, assuring the long-term survival of the companies (Kumarasiri, 2017; Stern, 2006). Therefore, an international commitment is imperative to achieve a reduction of global emissions, and avoid the negative impacts of this menace (Robinson \& Shine, 2018).

Another characteristic that can be identified is the role that non-governmental organizations (NGOs) play in bringing climate change closer to society. International organizations such as IPCC, UN, and academic institutions, are increasing the interest of the international community for the mitigation of emissions, motivating the transition to clean energies, aiming to the reduction of fossil fuels, and increasing the social concerns towards this threat (IPCC, 2018).

Secondly, organizational climate inaction is identified as a concept to be highlighted, where Slawinski et al. (2017) creates a classification related to the reduction of GHG emission. In this classification, emissions are grouped into three categories: symbolic, relative, and absolute. The first group is related to the minimum actions that are carried out by companies to achieve such reductions, having a limited impact. On the other hand, relative reduction decreases are aligned with the mitigation objective; however, they are insufficient to accomplish a significant impact that is necessary for the mitigation process. Lastly, absolute reductions are the most desirable because they are considered the final objective since they represent a significant reduction of these emissions, which is the fundamental goal of climate change mitigation.

Finally, there is an increasing number of companies adopting an environmental performance perspective caused to the different pressures from society to adopt this approach (Surugiu \& Surugiu, 2015). Companies are considered one of the main actors in climate change mitigation, based on their capabilities to design, develop and implement practices to contribute to declining the emissions released to the atmosphere (Dahlmann \& Grosvold, 2017; Santillán \& De la Vega, 2018).

Some limitations in the development of the study are recognized. First, we applied the Web of Science as the only engine, other platforms such as Scopus might be employed for future researches. Second, we restricted the manuscripts to only peer-review journal articles, being other types of documents accepted for the analysis. The third constraint identified are the keywords employed, for future research other keywords might be applied as well as to extend the time of exploration.

\section{Conclusions}

The literature review developed in this paper identifies the great threat posed by climate change indifference, from an economic and environmental perspective (Stern, 2013). Derived from this unpromising future, the private sector 
is considered as one of the main actors that can make a difference at the international level, since they have a great influence on the climate measures to reduce GHG emissions, and therefore, in climate change mitigation (Dahlmann \& Grosvold, 2017; Damert \& Baumgartner, 2017).

The interest of climate change in academic, business, and government areas has been increased based on the consequences that this climate crisis represents for the international community. Climate inaction in business has been already addressed in the literature; however, as Edmondson \& McManus (2007) suggests, in a nascent state of research, and open-ended inquiry about a phenomenon is established to invite to further work related to the happening, where the data included initially is open-ended to interpret the meaning, guiding to the creation of new constructs as well as pattern identification that might lead to a suggestive theory.

The literature review about climate inaction provides a new way of thinking related to the actions done by companies to reduce the inactivity towards climate change and motivate a change of paradigm to tackle this crisis that threatens the current way of living. Therefore, some suggestions can be developed based on this perspective:

- Which corporate practices might contribute to reducing climate inaction from the stakeholder perspective?

- What is the influence of the institutional logic shift towards practices aimed to reduce climate inaction in business?

- From the agency paradigm, how carbon performance might be enhanced to contribute to the reduction of inaction in business and management?

- From the RVB / NRBV perspective, how the capabilities of the company might contribute to the reduction of inaction towards climate change?

- What is the influence of corporate collective action in the mitigation process from a network perspective?

Conflict of interest statement: The authors of this paper can confirm that there is no conflict of interest involved with any matter presented in this manuscript.

\section{References}

Ackerman, F., \& Finlayson, I. J. (2006). The economics of inaction on climate change: A sensitivity analysis. Climate Policy, 6(5), 509-526. https://doi.org/10.1080/14693062.2006.9685617

Ackerman, F., \& Stanton, E. (2006). Climate Change- The Costs of Inaction. Retrieved from http://www.ase.tufts.edu/gdae/Pubs/rp/Florida_lr.pdf

Alrazi, B., De Villiers, C., \& Van Staden, C. J. (2015). A comprehensive literature review on, and the construction of a framework for, environmental legitimacy, accountability, and proactivity. Journal of Cleaner Production, 102, 44-57. https://doi.org/10.1016/j.jclepro.2015.05.022

Amran, A., Periasamy, V., \& Zulkafli, A. (2011). Determinants of climate change disclosure by developed and emerging countries in asia pacific. Sustainable Development, 22(3), 188-204. https://doi.org/10.1002/sd.539

Amran, A., Ooi, S. K., Wong, C. Y., \& Hashim, F. (2016). Business Strategy for Climate Change: An ASEAN Perspective. Corporate Social Responsibility and Environmental Management, 23(4), 213-227. https://doi.org/10.1002/csr.1371

Bamberg, S., Rees, J., \& Seebauer, S. (2015). Collective climate action: Determinants of participation intention in community-based pro-environmental initiatives. Journal of Environmental Psychology, 43, 155-165. https://doi.org/10.1016/j.jenvp.2015.06.006

Barman, E. (2018). Doing well by doing good: A comparative analysis of ESG standards for responsible investment. Advances in Strategic Management, 289-311.

Barrett, S., \& Dannenberg, A. (2014). Sensitivity of collective action to uncertainty about climate tipping points. Nature Climate Change, 4(1), 36-39. https://doi.org/10.1038/nclimate2059

Baumeister, R. (2013). Writing a literature review. In M. F. Prinstein (Ed.), The Portable Mentor - Expert Guide to a Successful Career in Psychology (pp. 119-132). Springer.

Burbidge, R. (2015). Avoiding the predictable surprise: Early action is the key to building a climate-resilient aviation network. Encyclopedia of Aerospace Engineering, 1-10.

Butler, M. P., Reed, P. M., Fisher-Vanden, K., Keller, K., \& Wagener, T. (2014). Inaction and climate stabilization uncertainties lead to severe economic risks. Climatic Change, 127(3-4), 463-474. 
https://doi.org/10.1007/s10584-014-1283-0

Cameron, K. S. (1986). Effectiveness as Paradox: Consensus and Conflict in Conceptions of Organizational Effectiveness. Management Science, 32(5), 539-553. https://doi.org/10.1287/mnsc.32.5.539

Carrington, D. (2013). Global carbon dioxide in atmosphere passes milestone level. The Guardian. Retrieved from https://www.theguardian.com/environment/2013/may/10/carbon-dioxide-highest-level-greenhouse-gas

Chakravarthy, B. S. (1986). Measuring strategic performance. Strategic Management Journal, 7(5), 437-458. https://doi.org/10.1002/smj.4250070505

Chen, W., Wu, F., Geng, W., \& Yu, G. (2017). Carbon emissions in China's industrial sectors. Resources, Conservation and Recycling, 117(B), 264-273.

Costoiu, M., Ioana, A., Semenescu, A., Constantin, N., Florea, B., Rucai, V., Dobrescu, C., Pollifroni, M., \& Păunescu, L. (2016). Environmental performance indicators for decision making and stakeholder interests. Environmental Engineering and Management Journal, 15(10), 2279-2284.

Dahlmann, F., \& Grosvold, J. (2017). Environmental Managers and Institutional Work: Reconciling Tensions of Competing Institutional Logics. Business Ethics Quarterly, 27(2), 263-291. https://doi.org/10.1017/beq.2016.65

Damert, M., \& Baumgartner, R. J. (2017). Intra-Sectoral Differences in Climate Change Strategies: Evidence from the Global Automotive Industry. Business Strategy and the Environment, 27(3), 265-281. https://doi.org/10.1002/bse.1968

De la Vega, A. (2015). Apuntes acerca del lugar del conocimiento económico en los análisis del IPCC. (U. Oswald, G. C. Delgado, \& X. Galvez (eds.)). UNAM-CIICH, Colección Alternativa.

Delmas, M., \& Blass, V. D. (2010). Measuring Corporate Environmental Performance: the Trade-Offs of Sustainability Ratings. Business Strategy and the Environment, 19, 245-260.

Duke, S., \& Bennett, H. (2010). A narrative review of the published ethical debates in palliatives care research and an assessment of their adequacy to inform research governance. Palliative Medicine, 24(2), 111-126.

Earth System Research Laboratory. (2018). Trends in the Atmospheric Carbon Dioxide. Global Greenhouse Gas Reference Network. Retrieved from http://www.esrl.noaa.gov/gmd/ccgg/trends/index.html

Edmondson, A. C., \& McManus, S. E. (2007). Fit in Methodological Management Field Research. Academy of Management Review, 32(4), 1155-1179.

Ehrenfeld, J. R., \& Hoffman, A. J. (2013). Flourishing: A frank conversation about sustainability. Stanford University Press.

European Comission. (2016). The Road from Paris: assessing the implications of the Paris Agreement and accompanying the proposal for a Council Decision on the signing, on behalf of the European Union, of the Paris Agreement adopted under the United Nations Framework Convention on Cl.

European Food Safety Authority. (2010). Application of systematic review methodology to food and feed safety assessments to support decision making. EFSA Journal, 8, 1-90.

Falkner, R. (2016). The Paris agreement and the new logic of international climate politics. International Affairs, 92(5), 1107-1125. https://doi.org/10.1111/1468-2346.12708

Finke, T., Gilchrist, A., \& Mouzas, S. (2016). Why companies fail to respond to climate change: Collective inaction as an outcome of barriers to interaction. Industrial Marketing Management, 58, 94-101. https://doi.org/10.1016/j.indmarman.2016.05.018

Funfgeld, H. (2015). Facilitating local climate change adaptation through transnational municipal works. Current Opinion in Environmental Sustainability, 12, 67-73.

GlobeScan. (2019). The Climate Decade. Ten years to deliver the Paris Agreement. Retrieved from https://globescan.com/webinar-2020-climate-survey-evaluating-progress/

Grant, M. J., \& Booth, A. (2009). A typology of reviews: An analysis of 14 review types and associated methodologies. Health Information and Libraries Journal, 26(2), 91-108. https://doi.org/10.1111/j.14711842.2009.00848.x

Green, B., Johnson, C., \& Adams, A. (2006). Writing narrative literature reviews for peer-reviewed journals: Secrets of the trade. Clinical Update, 5(3), 101-117. https://doi.org/10.1162/ling_a_00246 
Green, J. F. (2014). Rethinking Private Authority: Agents and Entrepreneurs in Global Environmental Governance. Princeton University Press.

Grigoroudis, E., Kanellos, F. D., Kouikoglou, V. S., \& Phillis, Y. A. (2016). Optimal abatement policies and related behavioral aspects of climate change. Environmental Development, 19, 10-22. https://doi.org/10.1016/j.envdev.2016.04.002

Guenther, E., Guenther, T., Schiemann, F., \& Weber, G. (2015). Stakeholder Relevance for Reporting: Explanatory Factors of Carbon Disclosure. Business and Society, 55(3), 361-397. https://doi.org/10.1177/0007650315575119

Haque, S., \& Azizul, M. (2015). Stakeholder pressures on corporate climate change-related accountability and disclosures: Australian evidence. Business and Politics, 17(2), 355-390.

Hart, S. L. (1995). A Natural-Resource-Based View of the Firm. The Academy of Management Review, 20(4), 9861014.

Heede, R. (2014). Tracing anthropogenic carbon dioxide and methane emissions to fossil fuel and cement producers, 1854-2010. Climatic Change, 122, 229-241. https://doi.org/10.1007/s10584-013-0986-y

Hoffman, A. J., \& Bazerman, M. (2007). Changing practice on sustainability: Understanding and overcoming the organizational and psychological barriers to action. (M. Sharma, M. Strarik, \& B. Husted (eds.)). Edward, Elgar.

Hope, C. W. (2006). The marginal impacts of CO 2, CH 4, and SF 6 emissions. Climate Policy, 6(January 2015), 537-544. https://doi.org/10.1080/14693062.2006.9685619

Howes, M., Tangney, P., Reis, K., Grant, D., \& Heazle, M. (2015). Towards networked governance: improving interagency communication and collaboration for disaster risk management and climate change adaptation in Australia. Journal of Environmental Planning and Management, 58(5), 757-776.

Ilinitch, A. Y., Soderstrom, N. S., \& Thomas, T. (1998). Measuring corporate environmental performance. Journal of Accounting and Public Policy, 17, 383-408.

IPCC. (2014). Cambio climático 2014. Impactos, adaptación y vulnerabilidad - Resumen para responsables de políticas. Contribución del Grupo de trabajo II al Quinto Informe de Evaluación del Grupo Intergubernamental de Expertos sobre el Cambio Climático.

IPCC. (2018). IPCC special report on the impacts of global warming of $1.5^{\circ} \mathrm{C}$ - Summary for policymakers (Issue October 2018). Retrieved from http://www.ipcc.ch/report/sr15/

Kelman, I. (2015). Climate Change and the Sendai Framework for Disaster Risk Reduction. International Journal of Disaster Risk Science, 6(2), 117-127. https://doi.org/10.1007/s13753-015-0046-5

Kenis, A., \& Lievens, M. (2015). Greening the Economy or Economizing the Green Project? When Environmental Concerns Are Turned into a Means to Save the Market. Review of Radical Political Economics, 48(2), 217 234. https://doi.org/10.1177/0486613415591803

Knuth, S., Nagle, B., Steuer, C., \& Yarnal, B. (2007). Universities and climate change mitigation: Advancing grassroots climate policy in the US. Local Environment: The International Journal of Justice and Sustainability, 12(5), 485-504. https://doi.org/10.1080/13549830701657059

Kumarasiri, J. (2017). Stakeholder pressure on carbon emissions: strategies and the use of management accounting. Australasian Journal of Environmental Management, 24(4), 339-354. https://doi.org/10.1080/14486563.2017.1350210

Li, Y., Gong, M., Zhang, X. Y., \& Koh, L. (2017). The impact of environmental, social, and governance disclosure on firm value: The role of CEO power. British Accounting Review, 50(1), 60-75. https://doi.org/10.1016/j.bar.2017.09.007

Mann, M. (2014). False Hope: The rate of global temperature rise may have hit a plateau, but a climate crisis still looms in the near future. Scientific American, 310, 78-81.

Mann, M., \& Kump, L. R. (2015). Dire predictions: Understanding climate change (2nd ed.). DK Publishing.

Mazutis, D., \& Eckardt, A. (2017). Sleepwalking into Catastrophe: Cognitive Biases and Corporate Climate Change Inertia. California Management Review, 59(3), 74-108. https://doi.org/10.1177/0008125617707974

Nature. (2018). The costs of climate inaction. Nature, 433-433. 
Pautasso, M. (2019). The Structure and Conduct of a Narrative Literature Review. In M. Shoja, A. Arynchyna, M. Loukas, A. D'Antoni, S. Buerger, M. Karl, \& R. Tubbs (Eds.), A Guide to the Scientific Career (1st ed., pp. 299-310). John Wiley \& Sons, Inc. https://doi.org/10.1002/9781118907283.ch31

Post, C., Rahman, N., \& McQuillen, C. (2015). From board composition to corporate environmental performance through sustainability-themed alliances. Journal of Business Ethics, 13(2), 423-435.

Robinson, M., \& Shine, T. (2018). Achieving a climate justice pathway to $1.5^{\circ} \mathrm{c}$. Nature Climate Change, $8(7)$, 564-569. https://doi.org/10.1038/s41558-018-0189-7

Santillán, M., \& De la Vega, A. (2018). Do the rich pollute more? Mexican household consumption by income level and CO2 emissions. International Journal of Energy Sector Management, 13(3), 694-712.

Silveria, J., \& Puppim, J. A. (2015). The role of the private sector in global climate and energy governance. Journal of Business Ethics, 130(2), 375-387.

Slavin, R. E. (1998). Best evidence synthesis: An intelligent alternative to meta-analysis. Journal of Clinical Epidemiology, 48, 9-18.

Slawinski, N., Pinkse, J., Busch, T., \& Banerjee, S. B. (2017). The Role of Short-Termism and Uncertainty Avoidance in Organizational Inaction on Climate Change: A Multi-Level Framework. Business and Society, 56(2), 253-282. https://doi.org/10.1177/0007650315576136

Stern, N. (2006). The Economics of Climate Change. Stern Review, 662. https://doi.org/10.1257/aer.98.2.1

Stern, N. (2013). The structure of economic modeling of the potential impacts of climate change: Grafting gross underestimation of risk onto already narrow science models. Journal of Economic Literature, 51(3), 838-859.

Sterner, T. (2015). Higher costs of climate change. Nature, 527, 177-178.

Sullivan, R., \& Gouldson, A. (2017). The Governance of Corporate Responses to Climate Change: An International Comparison. Business Strategy and the Environment, 26(4), 413-425. https://doi.org/10.1002/bse.1925

Surugiu, M., \& Surugiu, C. (2015). International Trade, Globalization, and Economic Interdependence between European Countries: Implications for Businesses and Marketing Framework. Procedia Economics and Finance, 32(15), 131-138. https://doi.org/10.1016/s2212-5671(15)01374-x

Talbot, D., \& Boiral, O. (2015). Strategies for Climate Change and Impression Management: A Case Study Among Canada's Large Industrial Emitters. Journal of Business Ethics, 132(2), 329-346. https://doi.org/10.1007/s10551-014-2322-5

Thompson, A., \& Otto, F. (2015). Ethical and normative implications of weather event attributions for policy discussions concerning loss and damage. Climate Change, 133(3), 439-451.

Tol, R. S. J., Downing, T. E., Kuik, O. J., \& Smith, J. B. (2004). Distributional aspects of climate change impacts. Global Environmental Change, 14(3), 259-272. https://doi.org/10.1016/0370-2693(74)90561-9

Tranfield, D., Denyer, D., \& Smart, P. (2003). Towards a methodology for developing evidence-informed management knowledge by means of systematic review. British Journal of Management, 14, 207-222. https://doi.org/10.2307/249689

United Nations. (1992). United Nations Framework Convention on Climate Change. Fccc/Informal/84, 1(3), 270 277. https://doi.org/10.1111/j.1467-9388.1992.tb00046.x

Walls, J. L., Berrone, P., \& Phan, P. H. (2012). Corporate governance and environmental performance: Is there really a link? Strategic Management Journal. https://doi.org/10.1002/smj

Wright, C., \& Nyberg, D. (2017). An inconvenient truth: How organizations translate climate change into business as usual. Academy of Management Journal, 60(5), 1633-1661. https://doi.org/10.5465/amj.2015.0718

Xiang, P., Zhang, H., Geng, L., Zhou, K., \& Wu, Y. (2019). Individualist-Collectivist Differences in Climate Change Inaction: The Role of Perceived Intractability. Frontiers in Psychology, 10(February), 1-12. https://doi.org/10.3389/fpsyg.2019.00187

Xie, J., Nozawa, W., Yagi, M., Fuji, H., \& Managi, S. (2018). Do environmental, social, and governance activities improve corporate financial performance? Business Strategy and the Environment, 28(2), 1-15.

Zadeh, A., \& Serafeim, G. (2017). Why and how investors use ESG information: Evidence from global survey. Financial Analysts Journal, 74(3), 1-17. 


\section{Copyrights}

Copyright for this article is retained by the author(s), with first publication rights granted to the journal.

This is an open-access article distributed under the terms and conditions of the Creative Commons Attribution license (http://creativecommons.org/licenses/by/4.0/). 